\title{
Broiler Tissue Enrichment with Docosahexaenoic Acid (DHA) through Dietary Supplementation with Aurantiochytrium limacinum Algae
}

\author{
Colm A. Moran' ${ }^{1}$ Jason D. Keegan², Kirsi Vienola ${ }^{3}$, Juha Apajalahti ${ }^{3}$ \\ ${ }^{1}$ Alltech SARL, Vire, France \\ ${ }^{2}$ Alltech's European Bioscience Centre, Dunboyne, Ireland \\ ${ }^{3}$ Alimetrics Ltd., Espoo, Finland \\ Email:cmoran@alltech.com
}

How to cite this paper: Moran, C.A., Keegan, J.D., Vienola, K. and Apajalahti, J. (2018) Broiler Tissue Enrichment with Docosahexaenoic Acid (DHA) through Dietary Supplementation with Aurantiochytrium limacinum Algae. Food and Nutrition Sciences, 9, 1160-1173.

https://doi.org/10.4236/fns.2018.910084

Received: September 10, 2018

Accepted: October 15, 2018

Published: October 18, 2018

Copyright (c) 2018 by authors and Scientific Research Publishing Inc. This work is licensed under the Creative Commons Attribution International License (CC BY 4.0).

http://creativecommons.org/licenses/by/4.0/

\begin{abstract}
The omega-3 fatty acid (n-3 FA) content of broiler tissues can be increased through dietary supplementation of hens with n-3 FA-rich microalgae. The aim of this study was to evaluate the effect of three different dietary inclusion levels of a docosahexaenoic acid (DHA)-rich microalgae (AURA) on broiler performance and the enrichment of tissues with n-3 FA. The randomized study was conducted using 352 birds, housed in 32 pens with 11 birds per pen. Pens were randomly assigned to one of four treatments, with each treatment replicated 8 times. The treatments included one unsupplemented control (0\%) and three wheat-soya based experimental diets supplemented with AURA at a level of $0.5 \%, 1.5 \%$ and $2.5 \%$ for the starter, grower and finisher periods. Birds were weighed on days $0,10,24,35$ and 41 , and feed intake was recorded per pen. On day 41, five birds per treatment were euthanized and individually weighed. Thigh muscle, breast muscle, liver, kidney and skin samples were taken post-mortem, freeze dried and DHA content quantified, following fat extraction and methylation, by GC-FID (AOAC 996.06 method). Performance and tissue data were analyzed by ANOVA with Dunnett's (2-sided) post-hoc test to determine the differences between the mean values for each treatment. Dietary supplementation with AURA had no effect on body weight or feed intake during any period of the study. For thigh muscle, kidney and skin the DHA increased linearly $(\mathrm{P}<0.05)$ with increasing level of dietary AURA, whilst there was a quadratic response in uptake of DHA in breast muscle and liver. The study demonstrated the potential of efficiently enriching broiler meat and organs with DHA by feeding AURA.
\end{abstract}




\section{Keywords}

Algae, Broilers, Meat, DHA Enrichment, Omega 3

\section{Introduction}

Consuming adequate amounts of omega-3 fatty acids (n-3 FA) can reduce the risk of various diseases including cardiovascular disease and depressive disorders [1] [2] [3]. However, Western diets are deficient in n-3 FA and high in omega-6 fatty acids ( $n-6$ FA), with a ratio of 15-20/1 n-6/n-3 compared to a more favorable $1 / 1$ ratio [4]. In recent years, this negative trend to a high n-6:n-3 ratio has being observed on a global basis and no longer a "Western" phenomenon, with reports of an urban Indian population consuming a diet with 38-50:1 n-6:n-3 [5] and concomitantly witnessing a sharp rise in obesity, diabetes and coronary heart disease [6] [7]. This is mainly due to a dietary shift to cereal grains and vegetable oils and a reduction in the consumption of green leafy vegetables, fruits, seeds and nuts [4]. Beyond the simple ratio the n-3 FA have important physiological roles in the human body. Docosahexaenoic (DHA) is one such n-3 FA which is essential for reproduction (production and protection of gametes) and early infant brain and nervous system development [8]. In adults, increased DHA intake has been linked to reduced heart disease, cardiac arrhythmia, atherosclerosis, diabetes and reduced risk of colon, prostate and breast cancers [9], [10]. However, in many countries daily n-3 FA consumption falls below the recommended level of $400-1000 \mathrm{mg}$ [11] [12] [13]. To address this deficiency, increasing human consumption of n-3 FA through the enrichment of commonly consumed foods, especially those foods derived from livestock and poultry production, has become the focus of much research [14].

Due to the simplicity of modifying FA composition of animal meat, milk or eggs through the diet, early attempts focused on two strategies, either through supplementation with fish meal or fish oils to provide EPA and DHA directly or alternatively to supplement flaxseed as a source of alpha linoleic acid (ALA n-3) [15]. However, there are drawbacks to both strategies which have impeded progress. Initially fishmeal and fish oil were considered expensive ingredients to use in the diets of agricultural species and more recently there are sustainability questions as to continued use, but more compelling for the consumer are the concerns regarding these ingredients imparting a "fishy" taste to the tissue [16]. Furthermore, the reduction in oxidative stability of both the feed and enriched animal tissue means a reduction in shelf-life with concerns for the distribution chain stakeholders and final consumer [17] [18].

Flaxseed can be a good source of omega-3, however it is required in higher doses which cause issues for formulators due to dilution of other nutrients in the feed and changes in processing quality when pelleting and crumbling, for example. Moreover, the addition of a high percentage of flaxseed in the diet has been 
associated with a laxative effect and poor uptake of nutrients in laying hens [19]. In recent years, research has focused on the use of marine heterotrophic microalgae as a source of DHA, such as those found at the base of the pelagic food chain. Rymer and coworkers [20] concluded that the algae Schizochytrium (DHA Gold) was as effective as fish oil in enriching broiler meat with omega-3, without changing oxidative stability and without the negative organoleptic properties. The use of microalgal oil has similar limitations as the use of fish oil in terms of oxidative stability and the ability to use in broiler feeds is restricted to a post-pellet application. Our research group has investigated the transfer efficiency of DHA from an unextracted heterotrophically grown Aurantiochytrium limacinum microalgal biomass to dairy milk [21] [22], pork meat and fat [23] [24] and laying hen eggs [25] [26]. For this study, the microalgal biomass was produced, following scale up from a pure culture, in a fed-batch production fermenter with a variable glucose feed and a fixed feed of urea and micronutrients. The culture was grown at $30^{\circ} \mathrm{C}$ for approximately 72 hours under sterile conditions. After adequate growth the content was harvested by centrifugation and concomitantly spray-dried to achieve approximately $67 \%$ crude fat, $16 \%$ DHA and $2 \%$ dry matter final product. Heterotrophic fermentation in a low salt media has been demonstrated to produce a microalgal biomass which protects the DHA and allows the ingredient to be added to feeds that undergo conditioning and pelleting, an essential part of modern broiler diet production [27].

The aim of the study was to evaluate the efficacy of the dietary inclusion of an unextracted Aurantiochytrium limacinum biomass, on the enrichment of select edible broiler chicken tissues, including breast meat, thigh meat, liver, kidney and skin with adhering fat.

\section{Materials and Methods}

\subsection{Animals and Housing}

The research protocol and animal care were in accordance with European Union Directive 2010/63/EU covering the protection of animals used for experimental or other scientific purposes. The 41-day trial was conducted in the broiler house of Alimetrics Ltd. in Southern Finland. 352-day-old broiler chicks were housed in 88 open pens $\left(1.125 \mathrm{~m}^{2}\right.$ each) with wood shavings litter, in an environmentally controlled room. Feed and water were supplied ad libitum for the 41-day study. Pens were randomly assigned to one of four dietary treatments, with each treatment replicated 8 times (11 birds per pen). Each chick was marked with permanent color to feathers to identify the treatment but not the individual animal. A veterinarian checked the health of the chicks at the beginning of the trial. The birds were observed twice a day. Chicks with compromised health were excluded from the trial.

The temperature of the barn was raised to $32^{\circ} \mathrm{C}$ two days before chicks arrived. Luminosity was adjusted to 20 lux and air humidity was adjusted according to recommendations. Brooder lamps were adjusted to provide extra heating 
to the chicks during the first week. The temperature was gradually decreased to $22^{\circ} \mathrm{C}$ over the rearing period. Temperature, ventilation and humidity was monitored and recorded throughout the experiment on a daily basis. The dark hours were gradually increased within a week, so that light-dark cycle was 18 hours light and 6 hours dark daily. The standard temperature and lighting program were followed.

\subsection{Dietary Treatments}

The diet was wheat-soy based feed for broiler chicks as specified in the Table 1. The starter formulation was fed during the first 10 days, grower diet for days 10 24 and finisher for the rest of the trial (24- 41 days). The starter diets were prepared as $2 \mathrm{~mm}$ pellets and the grower and finisher diets as $4 \mathrm{~mm}$ pellets. The feeds were manufactured at the Nature Resources Institute, Finland. Diets were formulated to meet or exceed the nutrient requirements according to the $\mathrm{Nu}$ trient Requirements of Poultry (1994) [28]. Birds were assigned to 1 of 4 isonitrogenous and isoenergetic diets: Control diet or treatment diets containing $0.5 \%, 1.5 \%$ or $2.5 \%$ heterotrophically grown, unextracted Aurantiochytrium limacinium (AURA; CCAP 4087/2) biomass, provided by Alltech Inc. (All-G-Rich ${ }^{\oplus}$, Nicholasville, KY, USA). AURA provided 0, 0.85, 2.55 and $4.25 \mathrm{~g}$ DHA $/ \mathrm{kg}$ for the respective treatment diets.

The analytical composition of AURA was determined using standardized and validated procedures (Association of Analytical Chemists, AOAC, USA) prior to the start of the study at Eurofins Nutrition Analysis Centre (Des Moines, USA): crude protein (AOAC 990.03), crude fat (AOAC 954.02), moisture (AOAC 930.15) and ash (AOAC 942.05). The fatty acid composition (AOAC 996.06) of AURA was determined at Mérieux NutriSciences (Burnaby, BC, Canada) in compliance with ISO 17025. In brief, fat and fatty acids were extracted from the algae biomass powder by acidic hydrolytic methods and subsequently into ether followed by methylation resulting in Fatty Acid Methyl Esters (FAMEs) using boron trifluoride $\left(\mathrm{BF}_{3}\right)$ in methanol. The FAME reference solution (GLC-85) and triundecanoin (C11:0) used as an internal standard for sample extraction were purchased from Nu-Chek-Prep Inc. (Minnesota, USA). The FAMEs were quantitively measured by gas chromatography equipped with a hydrogen flame ionization detector as described in Section 2.4.

\subsection{Performance}

Performance observations included live weight (d0, 10, 24, 35 and 41), feed intake (pen) and daily mortality. The feed conversion ratio was calculated and corrected for mortality. On day 41, five birds per treatment (20 birds total) were euthanized by cervical dislocation, coded, weighed individually, abdominal cavity opened and representative samples of the thigh and breast muscles (skinless), liver, kidney and skin (with adhering fat) were removed and stored in polyethylene bags frozen at $-20^{\circ} \mathrm{C}$ immediately. 
Table 1. Basic broiler control diets for the three phases of growth.

\begin{tabular}{cccc}
\hline & Starter $\%$ & Grower $\%$ & Finisher \% \\
& $0-10$ days & $10-24$ days & $24-41$ days \\
\hline Wheat & 59.84 & 64.17 & 65.79 \\
Soybean meal 48 & 31.80 & 27.90 & 25.50 \\
Sunflower oil & 3.60 & 3.46 & 4.50 \\
Monocalcium phosphate & 1.60 & 1.50 & 1.40 \\
Limestone & 1.65 & 1.55 & 1.48 \\
NaCl & 0.40 & 0.40 & 0.40 \\
Mineral premix & 0.20 & 0.20 & 0.20 \\
Vitamin premix & 0.20 & 0.20 & 0.20 \\
Methionine & 0.26 & 0.23 & 0.21 \\
L-Lysine HCl & 0.36 & 0.31 & 0.25 \\
Threonine & 0.09 & 0.08 & 0.07 \\
Total & 100 & 100 & 100 \\
MJ/kg & 12.42 & 12.55 & 12.92 \\
CP g/kg & 220.97 & 206.13 & 195.54 \\
\hline
\end{tabular}

${ }^{\mathrm{a}}$ Contents of the mineral premix: calcium $296.8 \mathrm{~g} / \mathrm{kg}$, iron $12.5 \mathrm{~g} / \mathrm{kg}$, copper $4 \mathrm{~g} / \mathrm{kg}$, manganese $25 \mathrm{~g} / \mathrm{kg}$, zinc $32.5 \mathrm{~g} / \mathrm{kg}$, iodine $0.225 \mathrm{~g} / \mathrm{kg}$, selenium $0.1 \mathrm{~g} / \mathrm{kg}$. ${ }^{\mathrm{b}}$ Contents of the vitamin premix: calcium $331.3 \mathrm{~g} / \mathrm{kg}$, vitamin A 6,000,000 IU, vitamin D3 2,250,000 IU, vitamin E 30000, tocopherol 27,270 mg/kg, vitamin K3 1505 $\mathrm{mg} / \mathrm{kg}$, vitamin B1 $1257.3 \mathrm{mg} / \mathrm{kg}$, vitamin B2 $3000 \mathrm{mg} / \mathrm{kg}$, vitamin B6 $2009.7 \mathrm{mg} / \mathrm{kg}$, vitamin B12 12.5 $\mathrm{mg} / \mathrm{kg}$, biotin $75 \mathrm{mg} / \mathrm{kg}$, folic acid $504 \mathrm{mg} / \mathrm{kg}$, niacin 20,072 mg/kg, pantothenic acid $7506.8 \mathrm{mg} / \mathrm{kg}$

\subsection{Broiler Fatty Acid Profile}

Fatty acid profiles of tissue and organ samples were determined at Mérieux $\mathrm{Nu}$ triSciences (Burnaby, BC, Canada) in compliance with ISO 17025. Recently, a GC-FID method (AOAC 996.06) was validated and verified to demonstrate the fitness for purpose in analyzing seven fatty acids in five different chicken tissues; i.e. breast, thigh, skin, kidney and liver [29]. In this method, fat and fatty acids are extracted from the breast tissue by hydrolytic methods. Samples of chicken tissues (liver, kidney, breast and thigh) were defrosted overnight in a refrigerator $\left(4^{\circ} \mathrm{C}\right)$ and ground thoroughly using a mortar and pestle. The ground samples were left in a freezer at $<-16^{\circ} \mathrm{C}$ for 12 hours prior to freeze drying. Frozen samples were freeze dried with VirTis Benchtop Pro Freeze Dryer (SP Scientific, Pennsylvania, USA) for 48 hours. Fat was extracted from $0.5 \mathrm{~g}$ sample of the homogenized freeze-dried tissue into ether, pyrogallic acid was added to minimize oxidative degradation of fatty acids during analysis, followed by methylation resulting in Fatty Acid Methyl Esters (FAMEs) using boron trifluoride $\left(\mathrm{BF}_{3}\right)$ in methanol.

The following fatty acid methyl ester standards were sourced from $\mathrm{Nu}$-Chek-Prep Inc. (Minnesota, USA); methyl

4,7,10,13,16,19-docosahexaenoate; methyl hexadecanoate; methyl

9-octadecenoate; methyl trans 9-octadecenoate; 9,12-methyl octadecadienoate; 
methyl trans 9,12-octadecadienoate, methyl 5,8,11,14,17 eicosapentaenoate. The internal standard for sample extraction, 1,2,3-triundecanoylglycerol (common name: triundecanoin), the internal standard for calibration curve and QCs, methyl undecanoate and docosahexaenoic acid (DHA) were also all purchased from Nu-Chek-Prep Inc. (Minnesota, USA). The Omega-3 Concentrate (Standard Reference Material 3275) was purchased from NIST (Gaithersburg, USA). FAMEs were quantitatively measured on an Agilent $6890 \mathrm{~N}$ gas chromatograph (Agilent, Ontario, Canada) equipped with a SP2560 $100 \mathrm{~cm}$ long capillary column, a hydrogen flame ionization detector (FID) set at $250^{\circ} \mathrm{C}$ temperature and an Agilent 7683 autosampler (Agilent, Ontario, Canada). Total fat was calculated as the sum of the individual fatty acids expressed as triglyceride equivalents and calculated back to wet tissue weight.

\subsection{Statistical Analysis}

Performance and tissue data were analyzed by the general linear model procedure of Minitab $^{\circledast}$ (Minitab $^{\circledast}$ version 18, State College, USA) with Dunnett's (2-sided) or Tukey's post-hoc tests used to determine the differences between the mean values for each treatment. For the ANOVA model, $\mathrm{p}<0.05$ indicated a significant difference. Regression analysis was used to determine the relationship between DHA intake and the DHA content of the broiler tissues or organs.

\section{Results and Discussion}

\subsection{Test Article Analysis and Zootechnical Performance}

The test article, AURA, used in this study primarily consisted of 70.2 g crude fat/100 $\mathrm{g}$ DM biomass and was composed of a significant level of palmitic acid and DHA, 35.97\% and $17.04 \%$ respectively (Table 2). Additionally, the AURA contained $13.1 \%$ crude protein, $3.2 \%$ ash and $2.2 \%$ moisture. The eicosapentaenoic acid (EPA; C20:5 n-3) content was low at 0.21\%. The total omega 3 and omega 6 isomers measured in AURA were 17.6\% and 4.5\%, respectively. Supplementation with AURA did not affect the various performance parameters measured, with no difference between the groups observed in health, mortality, weight, feed intake or feed conversion ratio observed over the course of the experiment (data not presented). The average final weight of the broiler chickens on day 41 , across treatment, was $3.59 \mathrm{~kg}$ with a FCR of 1.66.

\subsection{Enrichment of Meat and Organ Tissues}

The mean DHA content detected in the breast, thigh, liver and kidney and skin with adhering fat for each treatment group is presented in Table 3. In line with previous studies, supplementation with AURA resulted in an increased DHA content in all tissues [15] [20] [30] [31] [32] [33]. Each increase in AURA inclusion level resulted in a significant increase in tissue DHA content and with fatty tissues incorporating higher amounts of DHA. It is well documented that the fatty acid composition of the carcass reflects the fatty acid composition of the 
Table 2. Fatty acid composition (g/100 g dry matter biomass) of the unextracted Aurantiochytrium limacinum biomass used to supplement the experimental diets.

\begin{tabular}{|c|c|c|c|}
\hline Fatty Acid & $g / 100 \mathrm{~g}$ & Fatty Acid & $\mathrm{g} / 100 \mathrm{~g}$ \\
\hline C4:0 (Butyric acid) & $<0.01$ & C18:4 (Octadecatetraenoic acid) & 0.05 \\
\hline C6:0 (Caproic acid) & $<0.01$ & C20:0 (Arachidic acid) & 0.15 \\
\hline C8:0 (Caprylic acid) & $<0.01$ & C20:1 (Gadoleic acid + isomers) & $<0.01$ \\
\hline \multirow[t]{2}{*}{ Total Short Chain Fatty Acids } & $<0.01$ & C20:2 (Eicosadienoic acid) & $<0.01$ \\
\hline & & C20:3 (Eicosatrienoic acid - Omega 3) & $<0.01$ \\
\hline C10:0 (Capric acid) & $<0.01$ & C20:3 (di-homo-gamma-linolenic acid - Omega 6) & 0.10 \\
\hline C11:0 (Undecanoic acid) & $<0.01$ & C20:4 (Eicosatetraenoic acid - Omega 3) & 0.31 \\
\hline C12:0 (Lauric acid) & 0.10 & C20:4 (Arachidonic acid - Omega 6) & 0.05 \\
\hline C14:0 (Myristic acid) & 3.31 & C20:5 (Eicosapentaenoic acid - Omega 3) & 0.21 \\
\hline C14:1 (Myristoleic acid) & $<0.01$ & C21:5 (Heneicosapentaenoic acid - Omega 3) & $<0.01$ \\
\hline C15:0 (Pentadecanoic acid) & 0.24 & C22:0 (Behenic acid) & 0.08 \\
\hline C15:1 (Pentadecenoic acid) & $<0.01$ & C22:1 (Erucic + isomers) & $<0.01$ \\
\hline \multirow[t]{2}{*}{ Total Medium Chain Fatty Acids } & 3.65 & C22:2 (Docosadienoic acid - Omega 6) & $<0.01$ \\
\hline & & C22:3 (Docosatrienoic acid - Omega 3) & $<0.01$ \\
\hline C16:0 (Palmitic acid) & 35.97 & C22:4 (Docosatetraenoic acid - Omega 6) & $<0.01$ \\
\hline C16:1 Total (Palmitoleic acid + isomers) & 0.18 & C22:5 (Docosapentaenoic acid - Omega 3) & 0.04 \\
\hline C17:0 (Margaric acid) & 0.08 & C22:5 (Docosapentaenoic acid - Omega 6) & 4.22 \\
\hline C17:1 (Heptadecenoic acid) & $<0.01$ & C22:6 (Docosahexaenoic acid - Omega 3) & 17.04 \\
\hline C18:0 (Stearic acid) & 0.99 & Total Long chain fatty acids & 59.63 \\
\hline C18:2 (Linoleic acid + isomers) & 0.11 & & \\
\hline C18:3 (alpha linolenic acid - Omega 3) & 0.02 & & \\
\hline C18:3 (gamma linolenic acid - Omega6) & 0.03 & Total Fatty Acids & 63.68 \\
\hline
\end{tabular}

Table 3. The mean docosahexaenoic-acid (DHA) content (mg/100 g) of breast, thigh, liver and kidney, following dietary supplementation of broilers for 41 days with $0 \%, 0 . \% 5,1.0 \%$ or $2.5 \%$ unextracted Aurantiochytrium limacinum biomass.

\begin{tabular}{cllllll}
\hline & $0.0 \%$ & $0.50 \%$ & $1.00 \%$ & $2.50 \%$ & SEM & P-value \\
\hline Breast & $15.2^{\mathrm{d}}$ & $188.6^{\mathrm{c}}$ & $323.8^{\mathrm{b}}$ & $445.4^{\mathrm{a}}$ & 20.3 & $<0.001$ \\
Thigh & $16.2^{\mathrm{d}}$ & $201.6^{\mathrm{c}}$ & $469.2^{\mathrm{b}}$ & $835.8^{\mathrm{a}}$ & 26.7 & $<0.001$ \\
Liver & $62.1^{\mathrm{d}}$ & $514.0^{\mathrm{c}}$ & $835.0^{\mathrm{b}}$ & $1100.0^{\mathrm{a}}$ & 37.1 & $<0.001$ \\
Kidney & $42.7^{\mathrm{d}}$ & $196.5^{\mathrm{c}}$ & $290.0^{\mathrm{b}}$ & $423.8^{\mathrm{a}}$ & 10.4 & $<0.001$ \\
Skin with fat & $15.5^{\mathrm{c}}$ & $204.8^{\mathrm{c}}$ & $560.2^{\mathrm{b}}$ & $1208.6^{\mathrm{a}}$ & 49.0 & $<0.001$ \\
\hline
\end{tabular}

diet [15] [18] [20] [32] [34] [35]. Furthermore, the greater the concentration of fat in the tissue, the more total DHA was found as previously known from the literature [20] [32]. The Control breast meat (white) averaged $15.2 \mathrm{mg} / 100 \mathrm{~g}$ fresh edible tissue and in agreement with previous findings, $14-16.2 \mathrm{mg} / 100 \mathrm{~g}$ 
fresh edible tissue [15] [31] and lower than $24 \mathrm{mg} / 100 \mathrm{~g}$ fresh edible tissue reported by Rymer et al. [20]. The dietary addition of $0.5 \%$ AURA, providing 0.85 g DHA/kg diet, increased the DHA of breast meat $12.4 \mathrm{X}$ to $188.6 \mathrm{mg} / 100 \mathrm{~g}$ fresh meat. At the highest inclusion level in our study, 2.5\% AURA providing $4.25 \mathrm{~g}$ DHA/kg diet, improved the DHA content of the breast meat to $445.4 \mathrm{mg} / 100 \mathrm{~g}$ fresh edible meat. However, the literature is inconsistent at higher inclusion levels, Mooney and co-workers [30] reported a significantly lower concentration, $109 \mathrm{mg}$ DHA/100 g fresh breast meat, after feeding a 2.8\% Schizochytrium sp. biomass for the 4-week grower phase of the production cycle. Rymer and coworkers provided $7.5 \mathrm{~g}$ DHA/kg diet over the grower period and reported 187 $\mathrm{mg} / 100 \mathrm{~g}$ fresh breast meat [20] whilst Ribeiro and co-workers reported a 12.9X increase in breast DHA over the control [32]. Long and coworkers [33] found the opposite in their study, where a $2 \%$ microalgae supplementation resulted in a level of $5710 \mathrm{mg} / 100 \mathrm{~g}$ fresh breast meat.

The Control thigh meat (dark) averaged $16.2 \mathrm{mg} / 100 \mathrm{~g}$ fresh edible tissue and in general agreement with previous findings, $9-24 \mathrm{mg} / 100 \mathrm{~g}$ fresh edible tissue [15] [20] and [31]. The dietary addition of $0.5 \%$ AURA, providing $0.85 \mathrm{~g}$ DHA $/ \mathrm{kg}$ diet, resulted in a $12.4 \mathrm{X}$ increase in DHA content of thigh meat to 201.6 $\mathrm{mg} / 100 \mathrm{~g}$ fresh meat. Again, results at the upper inclusion levels, $1 \%$ AURA and higher proved to be difficult to compare to those values found in the literature [33]. At the higher inclusion level, providing $7.5 \mathrm{~g}$ DHA/kg diet, the dietary supplementation of a related Schizochytrium sp. microalgae biomass fed over the grower period resulted in $203 \mathrm{mg} / 100 \mathrm{~g}$ fresh thigh meat was reported following [20] and Ribeiro and co-workers reported a 14.3X increase in thigh DHA over the control [32].

A strong relationship was found between the dietary concentration of DHA and the DHA concentration in all tissues (Figure 1). Skin with adhering fat was enriched to the highest degree, with a linear increase $\left(R^{2}=0.9325, p<0.001, Y=\right.$ $27.48+1.587 \mathrm{X})$ in skin DHA content observed with increasing algae intake. The liver was the second most enriched, with a quadratic relationship observed $\left(\mathrm{R}^{2}=\right.$ $0.9435, \mathrm{p}<0.001, \mathrm{Y}=108.8+2.436 \mathrm{X}-0.001511 \mathrm{X}^{2}$ ) between intake and tissue content. As the liver plays an important role in lipid metabolism, this high concentration could be expected [36]. This quadratic relationship has been described by other authors [37] [38]. Thigh was the third most enriched with a linear relationship $\left(\mathrm{R}^{2}=0.9657, \mathrm{p}<0.001, \mathrm{Y}=21.70+1.086 \mathrm{X}\right)$ found between DHA intake and thigh DHA content. Breast, with less fat than thigh meat was enriched to a lesser degree, with a quadratic relationship observed $\left(R^{2}=0.9227\right.$, $\mathrm{p}<0.001, \mathrm{Y}=32.68+0.9349 \mathrm{X}-0.000520 \mathrm{X}^{2}$ ) between DHA intake and breast DHA content. Kidney was the least enriched with DHA content increasing linearly $\left(\mathrm{R}^{2}=0.9380, \mathrm{p}<0.001, \mathrm{Y}=75.57+0.4843 \mathrm{X}\right)$ with increasing DHA intake.

The incorporation of dietary DHA from fish or marine algae sources into poultry meat tissue has a long history, going back to the 1960's [15] [34] [35]. In 


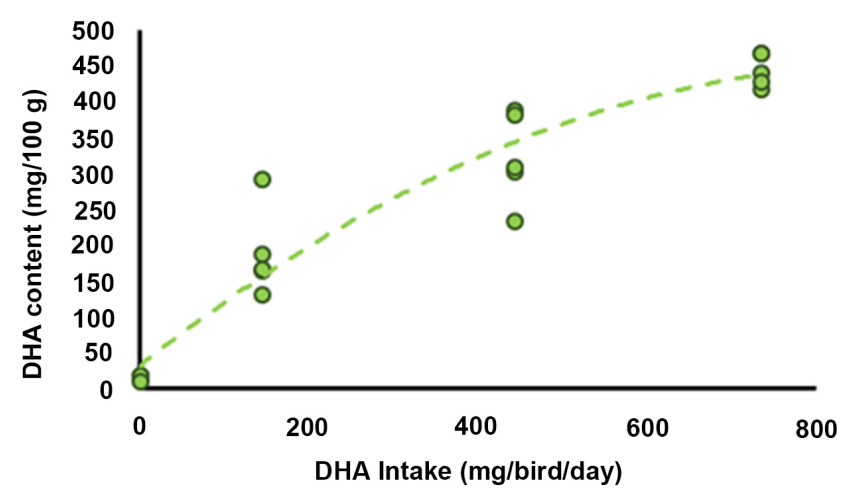

(a)

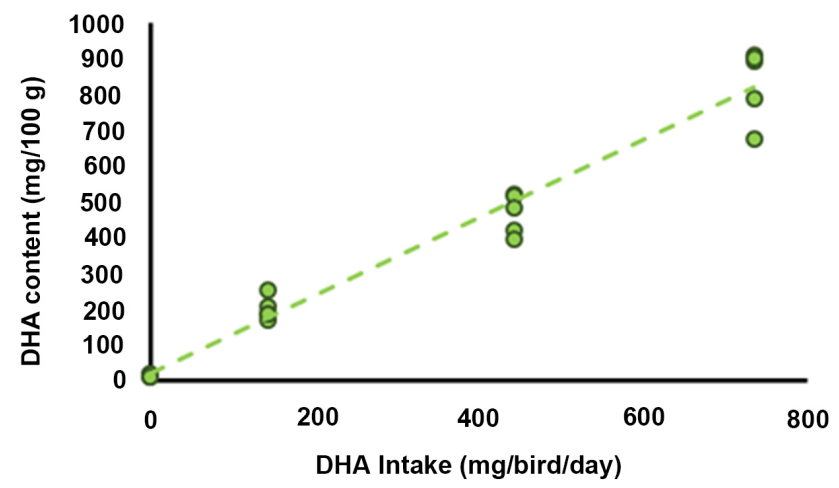

(b)

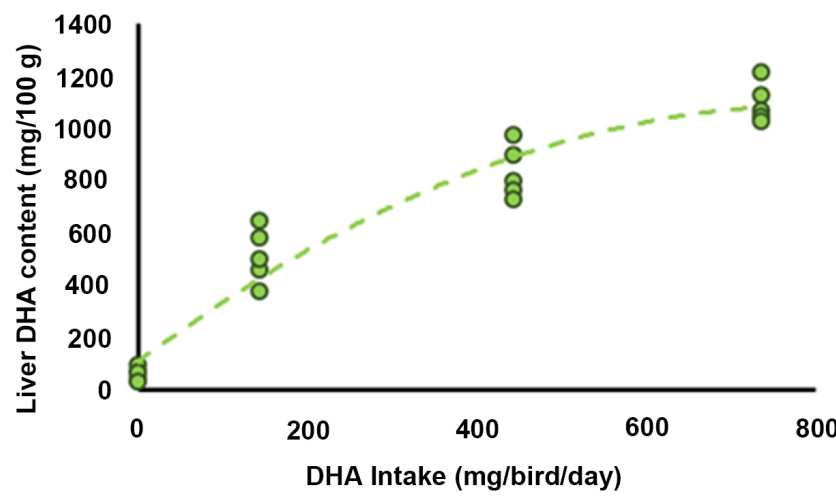

(d)

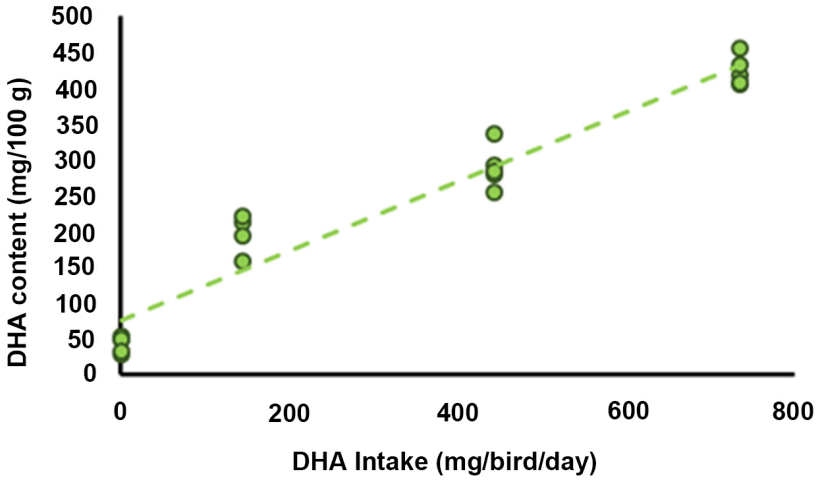

(c)

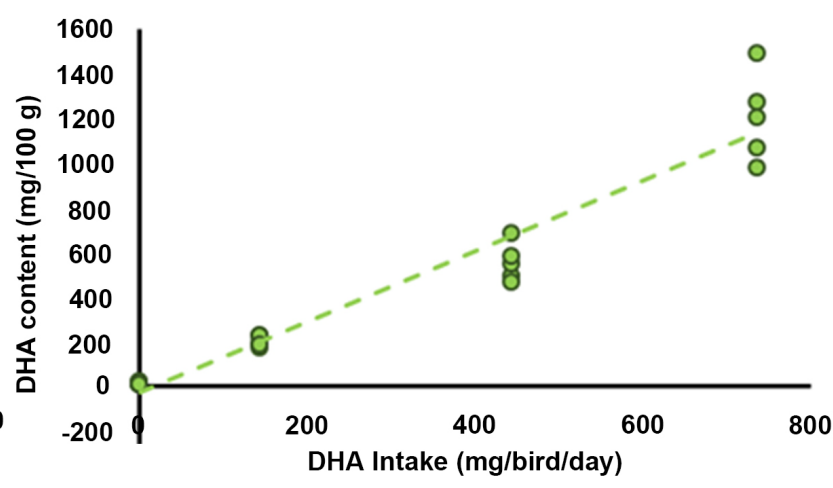

(e)

Figure 1. Scatterplot with regression lines for DHA intake (mg/bird/day) against the DHA content (mg/100 g) detected in the breast (a), thigh (b), kidney (c), liver (d) and skin with adhering fat (e).

contrast to our study findings, in a review of the literature, Rymer and Givens [15] found a poor relationship between DHA concentration in the diet and DHA content in the edible tissues of poultry; white meat, $\mathrm{R}^{2}=0.093$ and dark meat, $\mathrm{R}^{2}$ $=0.143$. The difference in results between studies may be due to a range of factors: importantly the total quantity of DHA fed to the broiler and the level of fat in the tissue at slaughter; i.e. a fattier carcass will have greater deposition of DHA. However, other factors are unknown or have a limited role in DHA transfer from feed to tissue: the duration of feeding (entire production cycle versus grower phase), the presentation of the DHA (protected from processing condi- 
tions, biomass or oil), the source of DHA being fed (fish or microalgae), the actual concentration of DHA measured in the feed (bioavailable versus estimated), and finally the differences between method of analysis and the time between sampling and analysis. Prior to our study, Dillon and co-workers [29] had validated the AOAC 996.06 method for analysis of DHA in the different poultry tissues. Their findings highlighted the necessity to analyze samples close to time of sampling and not to leave frozen for more than 3 months and in some cases the stability at $-20^{\circ} \mathrm{C}$ was very short with DHA loss appearing a within a month of storage.

This study shows the possibility of efficiently feeding broilers a source of sustainable n-3 FA (DHA) thereby producing a healthier DHA-enriched meat. An enriched poultry meat product that redresses nutritional imbalances in today's diet [14], with associated nutritional health claims [39] and with a lower greenhouse gas impact than other animal protein products (beef, pig etc) [40] is attractive for the modern educated consumer. Future work will need to look at the optimization of supplementation through back titrating the dose, length of time to feed and an economic cost evaluation along the production cycle. The current study only investigated the enrichment of tissue DHA but a more complete evaluation of the fatty acid profile of the meat including the contribution of docosapentaenoic acid (C22:5 n-3) and the omega-6/omega-3 ratio would be beneficial for the human nutritionist and consumer to evaluate the healthfulness of the chicken meat [15] [41]. Finally, a study investigating oxidative stability of the meat and consumer acceptability will need to be performed.

\section{Conclusion}

In conclusion, the dietary supplementation of an unextracted DHA-rich Aurantiochytrium limacinum biomass to a broiler diet for the entire production cycle (41 days) resulted in the significant and efficient transfer of DHA to the fat of the muscle, skin and organs, thereby improving the nutritional quality of the tissues for human consumption.

\section{Acknowledgements}

Funding for this work was provided by Alltech SARL (France). The authors would like to express their gratitude to Ms. Rebecca Timmons (Alltech USA) for her technical input on microalgae and Dr. Tuoying Ao for his knowledge of the application of microalgae in broiler nutrition

\section{Conflicts of Interest}

The authors Colm A. Moran and Jason D. Keegan work for Alltech who manufacture and market the ingredient All-G-Rich.

\section{References}

[1] Russo, G.L. (2009) Dietary n-6 and n-3 Polyunsaturated Fatty Acids: From Bioche- 
mistry to Clinical Implications in Cardiovascular Prevention. Biochemical Pharmacology, 77, 937-946. https://doi.org/10.1016/j.bcp.2008.10.020

[2] Rizos, E.C., Ntzani, E.E., Bika, E., Kostapanos, M.S. and Elisaf, M.S. (2012) Association between Omega-3 Fatty Acid Supplementation and Risk of Major Cardiovascular Disease Events: A Systematic Review and Meta-Analysis. JAMA, 308, 1024-1033. https://doi.org/10.1001/2012.jama.11374

[3] Marventano, S., Kolacz, P., Castellano, S., Galvano, F., Buscemi, S., Mistretta, A. and Grosso, G. (2015) A Review of Recent Evidence in Human Studies of n-3 and n-6 PUFA Intake on Cardiovascular Disease, Cancer, and Depressive Disorders: Does the Ratio Really Matter? International Journal of Food Sciences and Nutrition, 66, 611-622. https://doi.org/10.3109/09637486.2015.1077790

[4] Simopoulos, A.P. (2008) The Importance of the Omega-6/Omega-3 Fatty Acid Ratio in Cardiovascular Disease and Other Chronic Diseases. Experimental Biology and Medicine, 233, 674-688. https://doi.org/10.3181/0711-MR-311

[5] Pella, D., Dubnov, G., Singh, R.B., Sharma, R., Berry, E.M. and Manor, O. (2003) Effects of an Indo-Mediterranean Diet on the Omega-6/Omega-3 Ratio in Patients at High Risk of Coronary Artery Disease: The Indian Paradox. In: Omega-6/Omega-3 Essential Fatty Acid Ratio: The Scientific Evidence, KARGER, Basel, Vol. 92, 74-80. https://doi.org/10.1159/000073793

[6] Popkin, B., Horton, S., Kim, S., Mahal, A. and Shuigao, J. (2001) Trends in Diet, Nutritional Status, and Diet Related Non-Communicable Diseases in China and India: The Economic Costs of the Nutrition Transition. Nutrition Reviews, 59, 379-90. https://doi.org/10.1111/j.1753-4887.2001.tb06967.x

[7] WHO (2014) Global Status Report on Noncommunicable Diseases 2014. World Health Organization, 298.

[8] Stauffer, C.E. (1996) In Fats and Oils. American Association of Cereal Chemists Inc, Eagan Press, St Paul MN, USA. https://doi.org/10.1094/9780913250907

[9] Simopoulos, A.P. (2002) Omega-3 Fatty Acids in Inflammation and Autoimmune Diseases. Journal of the American College of Nutrition, 21, 495-505. https://doi.org/10.1080/07315724.2002.10719248

[10] Hartweg, J., Farmer, A.J., Holman, R.R. and Neil, A. (2009) Potential Impact of Omega-3 Treatment on Cardiovascular Disease in Type 2 Diabetes. Current Opinion in Lipidology, 20, 30-38. https://doi.org/10.1097/MOL.0b013e328321b3be

[11] European Food Safety Authority (2010) Scientific Opinion on Dietary Reference Values for Fats, Including Saturated Fatty Acids, Polyunsaturated Fatty Acids, Monounsaturated Fatty Acids, Trans Fatty Acids, and Cholesterol. EFSA Journal, 8, 1461 .

http://www.efsa.europa.eu/sites/default/files/scientific_output/files/main_document s/1461.pdf

[12] Meyer, B.J. (2011) Are We Consuming Enough Long Chain Omega-3 Polyunsaturated Fatty Acids for Optimal Health? Prostaglandins, Leukotrienes and Essential Fatty Acids, 85, 275-280. https://doi.org/10.1016/j.plefa.2011.04.010

[13] Papanikolaou, Y., Brooks, J., Reider, C. and Fulgoni, V.L. (2014) U.S. Adults Are Not Meeting Recommended Levels for Fish and Omega-3 Fatty Acid Intake: Results of an Analysis Using Observational Data from NHANES 2003-2008. Nutrition Journal, 13, 31. https://doi.org/10.1186/1475-2891-13-31

[14] Whelan, J. and Rust, C. (2006) Innovative Dietary Sources of N-3 Fatty Acids. Annual Review of Nutrition, 26, 75-103.

https://doi.org/10.1146/annurev.nutr.25.050304.092605 
[15] Rymer, C. and Givens, D.I. (2005) n-3 Fatty Acid Enrichment of Edible Tissue of Poultry: A Review. Lipids, 40, 121-130. https://doi.org/10.1007/s11745-005-1366-4

[16] Gonzalez-Esquerra, R. and Leeson, S. (2000) Effect of Feeding Hens Regular or Deodorized Menhaden Oil on Production Parameters, Yolk Fatty Acid Profile, and Sensory Quality of Eggs. Poultry Science, 79, 1597-1602.

https://doi.org/10.1093/ps/79.11.1597

[17] Hulan, H.W., Ackman, R.G., Ratnayake, W.M.N. and Proudfoot, F.G. (1988) Omega-3 Fatty Acid Levels and Performance of Broiler Chickens Fed Redfish Meal or Redfish Oil. Canadian Journal of Animal Science, 68, 533-547. https://doi.org/10.4141/cjas88-059

[18] Manilla, H.A. and Husveth, F. (1999) n-3 Fatty Acid Enrichment and Oxidative Stability of Broiler Chicken (A Review). Acta Alimentaria, 28, 235-249.

https://doi.org/10.1556/AAlim.28.1999.3.3

[19] Coorey, R., Novinda, A., Williams, H. and Jayasena, V. (2015) Omega-3 Fatty Acid Profile of Eggs from Laying Hens Fed Diets Supplemented with Chia, Fish Oil, and Flaxseed. Journal of Food Science, 80, S180-S187.

https://doi.org/10.1111/1750-3841.12735

[20] Rymer, C., Gibbs, R.A. and Givens, D.I. (2010) Comparison of Algal and Fish Sources on the Oxidative Stability of Poultry Meat and Its Enrichment with Omega-3 Polyunsaturated Fatty Acids. Poultry Science, 89, 150-159. https://doi.org/10.3382/ps.2009-00232

[21] Moran, C.A., Morlacchini, M. and Fusconi, G. (2017) Enhancing the DHA Content in Milk from Dairy Cows by Feeding ALL-G-RICH ${ }^{\mathrm{Tm}}$. Journal of Applied Animal Nutrition, 5, 1-9. https://doi.org/10.1017/jan.2017.9

[22] Moran, C.A., Morlacchini, M., Keegan, J.D. and Fusconi, G. (2018) The Effect of Dietary Supplementation with Aurantiochytrium limacinum on Lactating Dairy Cows in Terms of Animal Health, Productivity and Milk Composition. Journal of Animal Physiology and Animal Nutrition, 102, 576-590. https://doi.org/10.1111/jpn.12827

[23] Moran, C.A., Morlacchini, M., Keegan, J.D. and Fusconi, G. (2018) Dietary Supplementation of Pigs with the Docosahexaenoic-Rich Microalgae, Aurantiochytrium limacinum: Effects on Performance, Carcass Characteristics and Tissue Fatty Acid Profile. Asian-Australasian Journal of Animal Science, 31, 712-720. https://doi.org/10.5713/ajas.17.0662

[24] Moran, C.A., Morlacchini, M., Keegan, J.D., Delles, R. and Fusconi, G. (2018) Effects of a DHA-Rich Unextracted Microalgae as a Dietary Supplement on Performance, Carcass Traits, and Meat Fatty Acid Profile in Growing-Finishing Pigs. Journal of Animal Physiology and Animal Nutrition, 102, 1026-1038.

https://doi.org/10.1111/jpn.12911

[25] Ao, Y., Macalintal, L.M., Paul, M.A., Pescatore, A.J., Cantor, A.H., Ford, M.J., Timmons, B. and Dawson, K.A. (2015) Effects of Supplementing Microalgae in Laying Hen Diets on Productive Performance, Fatty Acid Profile and Oxidative Stability of Eggs. Journal of Applied Poultry Research, 24, 394-400. https://doi.org/10.3382/japr/pfv042

[26] Moran, C.A., Morlacchini, M., Ao, T., Keegan, J.D. and Fusconi, G. (2018) Increasing the Omega-3 Content of Hen's Eggs through Dietary Supplementation with the Microalgae, Aurantiochytrium limacinum (All-G-Rich ${ }^{\oplus}$ ). Poultry Science, 97(E-Suppl. 1), 177.

[27] Moran, C., Currie, D. and Knox, A. (2017) Does Pelleting Affect Transfer of DHA 
to Eggs When Heterotrophically-Grown Microalgae Are Added to Layer Diets? Poultry Science, 96(E-Suppl. 1), 295.

[28] National Research Council (1994) Nutrient Requirements of Poultry. 9th Revised Edition, National Academy Press, Washington DC.

[29] Dillon, G., Brandl, W., Cardinall, C., Yuan, W., Groenewegen, P., Yiannikouris, A. and Moran, C.A. (2018) GC-FID Method Validation and Stability of DHA in Chicken Tissues. Poultry Science, 97(E-Suppl. 1), 191.

[30] Mooney, J.W., Hirschler, E.M., Kennedy, A.K., Sams, A.R. and Van Elswyk, M.E. (1998) Lipid and Flavour Quality of Stored Breast Meat from Broilers Fed Marine Algae. Journal of the Science of Food and Agriculture, 78, 134-140. https://doi.org/10.1002/(SICI)1097-0010(199809)78:1<134::AID-JSFA96>3.0.CO;2$\underline{0}$

[31] Abril, R. and Barclay, W. (1998) Production of Docosahexaenoic Acid-Enriched Poultry Eggs and Meat Using an Algae-Based Feed Ingredient. In: Simopoulos, A.P., Ed., The Return of $\omega 3$ Fatty Acids into the Food Supply. I. Land-Based Animal Food Products and Their Health Effects, World Rev. Nutr. Diet, Basel, Vol. 83, 77-88. https://doi.org/10.1159/000059654

[32] Ribeiro, T., Lordelo, M.M., Alves, S.P., Bessa, R.J.B., Costa, P., Lemos, J.P.C., Ferreira, L.M.A., Fontes, C.M.G.A. and Prates, J.A.M. (2013) Direct Supplementation of Diet Is the Most Efficient Way of Enriching Broiler Meat with n-3 Long-Chain Polyunsaturated Fatty Acids. British Poultry Science, 54, 753-765. https://doi.org/10.1080/00071668.2013.841861

[33] Long, S.F., Kang, S., Wang, Q.Q., Xu, Y.T., Pan, L., Hu, J.X., Li, M. and Piao, X.S. (2018) Dietary Supplementation with DHA-Rich Microalgae Improves Performance, Serum Composition, Carcass Trait, Antioxidant Status, and Fatty Acid Profile of Broilers. Poultry Science, 97, 1881-1890. https://doi.org/10.3382/ps/pey027

[34] Zduńczyk, Z. and Jankowski, J. (2013) Poultry Meat as Functional Food: Modification of the Fatty Acid Profile-A Review. Annals of Animal Science, 13, 463-480. https://doi.org/10.2478/aoas-2013-0039

[35] Marion, J.E. and Woodrooff, J.G. (1963) The Fatty Acid Composition of Breast, Thigh, and Skin Tissues of Chicken Broilers as Influenced by Dietary Fats. Poultry Science, 48, 1202-1207. https://doi.org/10.3382/ps.0421202

[36] Nguyen, P., Leray, V., Diez, M., Serisier, S., Le Bloc'h, J., Siliart, B. and Dumon, H. (2008) Liver Lipid Metabolism. Journal of Animal Physiology and Animal Nutrition, 92, 272-283. https://doi.org/10.1111/j.1439-0396.2007.00752.x

[37] Neijat, M., Ojekudo, O. and House, J.D. (2016) Effect of Flaxseed Oil and Microalgae DHA on the Production Performance, Fatty Acids and Total Lipids of Egg Yolk and Plasma in Laying Hens. Prostaglandins, Leukotrienes and Essential Fatty Acids, 115, 77-88. https://doi.org/10.1016/j.plefa.2016.10.010

[38] Neijat, M., Eck, P. and House, J.D. (2017) Impact of Dietary Precursor ALA versus Preformed DHA on Fatty Acid Profiles of Eggs, Liver and Adipose Tissue and Expression of Genes Associated with Hepatic Lipid Metabolism in Laying Hens. Prostaglandins, Leukotrienes and Essential Fatty Acids, 119, 1-17. https://doi.org/10.1016/j.plefa.2017.01.010

[39] Grunert, K.G., Verbeke, W., Kugler, J.O., Saaed, F. and Scholderer, J. (2011) Use of Consumer Insight in the New Product Development Process in the Meat Sector. Meat Science, 89, 251-258. https://doi.org/10.1016/j.meatsci.2011.04.024

[40] Fiala, N. (2008) Meeting the Demand: An Estimation of Potential Future Greenhouse Gas Emissions from Meat Production. Ecological Economics, 67, 412-419. 
https://doi.org/10.1016/j.ecolecon.2007.12.021

[41] Kaur, G., Cameron-Smith, D., Garg, M. and Sinclair, A.J. (2011) Docosapentaenoic Acid (22:5n-3): A Review of Its Biological Effects. Progress in Lipid Research, 50, 28-34. https://doi.org/10.1016/j.plipres.2010.07.004 